\title{
ABSTRACT \\ ASSESSMENT OF DATA RESOURCES IN THE CONSTRUCTION OF LATE ORDOVICIAN SHALLOW MARINE FOOD WEBS: DATA COMPILATIONS VERSUS MUSEUM COLLECTIONS
}

\author{
by Ian Omar Castro
}

The fossil record contains ecosystem changes, and can provide insights into ecological conditions over evolutionary timescales, particularly factors affecting community structure before and after disturbance. Our current understanding of these effects is based on changes in biodiversity, which cannot capture interactions between organisms. Food webs provide an alternative approach, representing interactions within a community. Food webs present unique challenges as they require assembling paleocommunity data for species across trophic levels. Numerous sources may be used to determine the species present in a paleocommunity. However, the potential effects of differences between data derived from museum collections and data compilations have not yet been tested. Here we examined differences between food web models of Late Ordovician marine communities assembled using two types of data: museum collections and field work; and the PBDB. To determine whether both data types produced consistent outcomes, paleocommunities were compared before and after the Richmondian Invasion. Relative differences in model outcomes across the invasion did not vary between data types. Differences in structure were consistent between the datatypes, with similar changes across the invasion. These findings suggest that both data types may be suitable for studies examining differences in resistance. 


\title{
ASSESSMENT OF DATA RESOURCES IN THE CONSTRUCTION OF LATE ORDOVICIAN \\ SHALLOW MARINE FOOD WEBS: DATA COMPILATIONS VERSUS MUSEUM COLLECTIONS
}

\author{
A Thesis \\ Submitted to the \\ Faculty of Miami University \\ in partial fulfillment of \\ the requirements for the degree of \\ Master of Science \\ by \\ Ian Omar Castro \\ Miami University \\ Oxford, Ohio \\ 2018 \\ Advisor: Dr. Carrie Tyler \\ Reader: Dr. Hailiang Dong \\ Reader: Dr. Michael Brudzinski \\ Reader: Dr. Peter Roopnarine
}

(C2018 Ian Omar Castro 
This thesis titled

\section{ASSESSMENT OF DATA RESOURCES IN THE CONSTRUCTION OF LATE ORDOVICIAN SHALLOW MARINE FOOD WEBS: DATA COMPILATIONS VERSUS MUSEUM COLLECTIONS}

by

Ian Omar Castro

has been approved for publication by

The College of Arts and Science

and

Department of Geology and Environmental Earth Science

Dr. Carrie Tyler (Thesis Advisor)

Dr. Hailiang Dong (Committee Member)

Dr. Michael Brudzinski (Committee Member) 


\section{Table of Contents}

List of Tables..........................................................

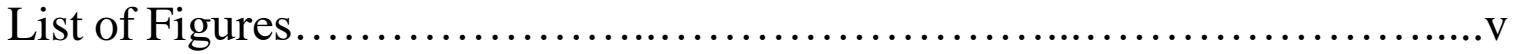

Dedication............................................................

Acknowledgements..............................................vii

Introduction........................................................

Geologic Setting ....................................................2

Methods..................................................................

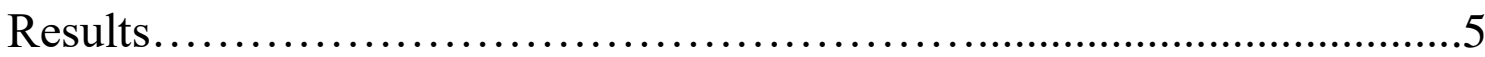

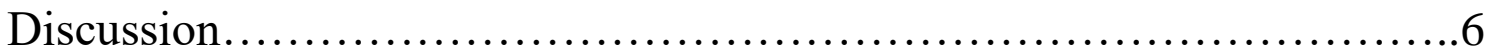

Conclusions.....................................................

References.........................................................

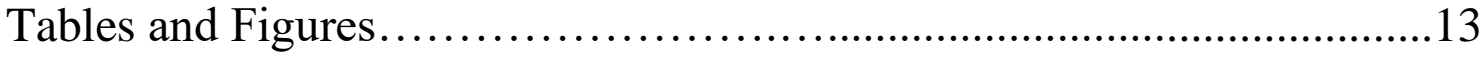




\section{List of Tables}

Table 1: Species counts...........................................13

Table 2: Metrics comparison table....................................13

Table 3: Guilds present in datasets..................................... 14 


\section{List of Figures}

Figure 1: Depositional sequences and lithology........................15

Figure 2: Field locality map.............................................. 16

Figure 3: Cascading Extinction of Graphs (CEG) models...................17

Figure 4: Network guild visualizations.................................18 


\section{Dedication}

I dedicate this research to my parents, Artemio Castro and Mayra Castro, for their endless support in my career and for always encouraging my dreams. 


\section{Acknowledgements}

I would like to acknowledge Dr. Carlton Brett of the University of Cincinnati for assistance with field collection and project guidance, Tim Paton for help with fossil identification and field collection, Dr. Kendall Hauer for access to Miami University paleontological collections, Dr. Ashley Dineen for research assistance, and Dr. Brenda Hunda for access to the Cincinnati Museum Center invertebrate collections. I also want to thank my research partner, Hannah Kempf, for her collaboration and feedback throughout my research project and I would like to thank my fellow paleontology lab members, Lyndsey Farrar and Melanie Sorman, for assisting with graph creation and help using programming software.

I would also like to acknowledge the Department of Geology and Environmental Earth Sciences at Miami University and the Dry Dredgers for supporting this research.

I want to thank my advisor, Dr. Carrie Tyler, for agreeing to work with me and for supervising my research. I want to thank my committee members, Dr. Peter Roopnarine and Dr. Hailiang Dong, for their guidance throughout this research project. I also want to give thanks to my parents, my younger brother Jose Castro, and my friend Cory McPhillips for their assistance with sample collection.

Finally, I would like to thank Dr. Brooke Crowley for supporting me as my undergraduate research advisor and Dr. David Meyer who put me into contact with my current advisor and provided me with the opportunity to begin graduate school research. 


\section{Introduction}

Ecological records predating anthropogenic effects are increasingly in demand to understand ecosystem functioning, and to establish baseline conditions prior to human disturbance (Jackson et al. 2001; Willis \& Birks 2006; Froyd \& Willis 2008). As species richness is not a reliable proxy for the types of interactions between organisms (i.e., functional diversity), changes in richness alone are insufficient to capture structural changes in communities, particularly relating to the intensity or number of interactions among species and between trophic levels. Furthermore, functional diversity may be more meaningful than species diversity, and associated with greater long-term ecosystem stability (O'Gorman et al. 2011; Cadotte et al. 2011). One solution to this problem, is to examine species connected through trophic relationships (Williams \& Martinez 2000; Paine 1992; McCann et al. 1998) defining complex networks, known as food webs.

The construction of food webs in the fossil record requires a comprehensive list of taxa present in the community (Roopnarine, 2010). Species lists can be assembled through field sampling, museum collections, or the literature, however, community composition may differ between these sources. Thus, networks representing the same paleocommunity, but produced using different sources, may not consistently reproduce network structure. Here we compare the structure and functioning of modeled paleocommunity dynamics and network topology between combined museum collections and field collected material, and online data repositories, specifically the Paleobiology Database (PBDB).

There are several ways in which specimen-based data (SB) and data from online databases, such as the Paleobiology Database (PBDB), may differ. The PBDB archives data from scientific publications encompassing a wide range of ecosystems, with broad spatio-temporal coverage. These data may differ in scope and resolution relative to smaller datasets compiled by individual researchers. In some cases, the PBDB may have a larger species pool than is likely to be assembled over the duration of a single study or field season. As higher trophic levels are frequently represented by rare taxa and species, a larger species pool may be more likely to include taxa from higher trophic levels. In addition, for some taxonomic groups, species identification can be particularly challenging. Bryozoans, for example, require thin sections and extensive experience to identify to the species level. In cases where samples entered into the PBDB were collected, identified, and verified by taxonomic experts, these data may more accurately document the species present in a paleocommunity (Alroy 2003). Alternatively, data may suffer from outdated taxonomic classifications, incorrect geographical data, and missing key species, attributed to outdated identification or classifications employed during data entry, a lack of filters for taxonomic wastebasket terms, and transcription errors (Prothero 2015). Taxonomic classifications used in museum collections that are re-checked and updated may be more reliable, for example, at institutions with strong research backgrounds for the taxa, region, or geologic intervals represented (Ponder et al, 2010). However, collections can be biased towards higher quality specimens intended for display or taxonomic description and identification, potentially omitting poorly preserved taxa or taxa already highly abundant in the collection, reducing the species richness for a locality or region (Alroy 2002). Paleocommunities assembled through field work and/or museum collections can also be biased by the taxonomic expertise of the collectors, concentrating collection efforts to portions of the paleocommunity, or increasing the accuracy of species identifications for some groups. These issues are important to consider when reconstructing food webs, as the inclusion or omission of key species, could alter trophic structure. 
Therefore, to determine how input data type affected paleocommunity trophic structure, food web models were repeatedly constructed for the same Late Ordovician shallow marine paleocommunities using two sources: specimen-based data, represented by a combination of museum collections and field collected material, and the PBDB. Food web structure and functioning was modeled before and after the Richmondian Invasion (Holland \& Patzkowsky 2007) using each data type to compare paleocommunity dynamics and network topology. If both data types yield comparable relative differences in paleocommunity structure and functioning across the invasion, this would suggest that either data source are acceptable for paleo-food web reconstruction.

\section{Geologic Setting}

The study area consists of the upper Ordovician Cincinnatian series which includes the Cincinnati arch of Ohio, Indiana, and Kentucky (Holland 1993; Pope \& Read 1997; Holland \& Patzkowsky 2007). This is the type area for the Cincinnatian series, and encompasses the Richmondian Invasion, a well-documented biotic invasion in shallow marine ecosystems (Holland \& Patzkowsky 2007). This area was distal of the Taconic foreland basin during the Late Ordovician (Holland 1993), and consisted of a gently dipping carbonate ramp in a shallow (<30 m) inland sea located 20 degrees south of the paleoequator (McKerrow \& Scotese, 1990). The sequence stratigraphic framework is well defined, and is composed of six depositional sequences: C1 through C6 (Figure 2). Four depositional environments are present (Brett \& Baird, 1986; Frey \& Pemberton, 1985; Holland, 1993): offshore, deep subtidal, shallow subtidal, and peritidal.

During the Richmondian Invasion, the Cincinnati region was invaded by taxa from the paleoequatorial region of Canada and the western United States (Holland, 1997). The invasion occurred during the $\mathrm{C} 4$ sequence and the invaders consisted primarily of brachiopods, bryozoans, and corals (Holland \& Patzkowsky 2007; Malizia \& Stigall 2011; Stigall 2010). Here we reconstruct the basin-wide shallow marine ecosystem using laterally adjacent shallow subtidal and deep subtidal paleoenvironments in sequence C2 and C5, pre- and post-invasion respectively. These lithologic units represent a continuous habitat above storm wave base exploited by organisms that likely interacted, representing the shallow marine ecosystem. Deeper facies contain storm dominated deposits of fossil material transported from shallower environments (Holland 1993; Pope \& Read 1997), and were thus excluded. Fossils were collected from four formations, two pre- and two post-invasion. The Fairview (deep-subtidal) and Bellevue (shallow-subtidal) formations (Maysvillian stage) represent the pre-invasion C2 sequence (Malizia \& Stigall 2011) and the Liberty (deep-subtidal) and Whitewater (shallow-subtidal) formations (Richmondian stage) from the post-invasion C5 sequence (Malizia \& Stigall 2011). These formations are highly fossiliferous and thus yielded adequate numbers of specimens.

\section{Methods}

To determine whether food web models constructed using specimen based data and the PBDB were consistent, and reproduced comparable relative structural changes in the face of ecological reorganization, four paleo-food web models were constructed, two before and two after the Richmondian Invasion (late C3 to early C5 sequences). Pre- and post-invasion specimen-based (SB) taxonomic lists were assembled using a combination of museum collections and field work 
(Table 1). Museum collections largely consisted of the Miami University Karl E. Limper Museum Invertebrate Collections and the Cincinnati Museum Invertebrate Collections, but also included the following collections downloaded from the Integrated Digitized Biocollections (iDigBio; October 21 $\left.{ }^{\text {st }}, 2016\right)$ : The Ohio University Invertebrate Paleontology collection, the Harvard Museum of Comparative Zoology collection, the Oklahoma Museum of Natural History Collection, the Kansas University Collection, the Smithsonian Institution National Museum collection, the University of Florida Invertebrate Paleontology Collection, the University of Central Missouri Collection, and the North Carolina Museum of Natural Science Collection (Table 1). Museum collections data were augmented with field sampling to increase the proportion of species with controlled metadata (e.g., geographic location and formation) and unbiased collecting. Field sampling included 20 localities, 10 pre- and 10 post-invasion (Figure 2) using surficial sampling. Samples were washed and sieved (1 mm mesh size) to remove excess mud and dirt, and specimens were identified to the lowest possible taxonomic level using taxonomic guides (Davis \& Meyer, 2009; Feldman \& Hackathorn, 1996; Williams et al, 2000), yielding a total of 5,867 specimens. Taxonomic lists were download from the PBDB (November $9^{\text {th }}, 2016$ ) for the preinvasion Fairview and Bellevue formations ( $\mathrm{C} 2$ sequence), and the post-invasion Liberty and Whitewater formations (C5 sequence; Table 1). Pre- and post-invasion specimen-based (SB) taxonomic lists were assembled using a combination of museum collections and field work (Table 1).

Food web models were used to compare paleocommunity dynamics and structure between the two types of data (SB and PBDB) across the Richmondian Invasion. Paleocommunities before and after the Richmondian Invasion may differ, as the invasion is thought to have resulted in community reorganization (Patzkowsky \& Holland, 1996; Patzkowsky \& Holland, 2007) due to the introduction of new species, extinction of incumbents potentially leading to changes in the number of guilds or trophic levels. Therefore, pre- and post-invasion models were constructed separately using SB data and the PBDB for a total of four models. Due to the uncertainty associated with paleontological data and assigning biotic interactions in the fossil record, a paleocommunity's trophic network can never be specified by a single network topology, and even in modern systems, we cannot identify all possible interactions between organisms in an ecosystem. Therefore, network stability and paleocommunity dynamics were assessed for each of the four paleocommunities using Cascading Extinction on Graphs (CEG) models (Roopnarine 2006; Roopnarine 2009; Roopnarine \& Dineen 2018). Models were constructed by first assembling comprehensive species lists of members of each community (Roopnarine 2009; Roopnarine 2010). Many examples of older nomenclature, different names being used for the same species, misspellings, and various other errors were encountered in both datasets. This was most common with brachiopods, where both outdated and revised genera were included, e.g., both "Vinlandostrophia" and "Platystrophia" were present. This issue may be a more common in museums with very old collections that have not been regularly updated.

Species were then assigned to trophic guilds, groups of organisms that utilize resources in the same way and are trophically indistinct. Trophic guilds were then linked to each other if species within those guilds have the potential for trophic interactions (predators or prey), creating a guild metanetwork which constrains the model (Roopnarine 2010). Trophic interactions were assigned using extensive literature surveys on life-mode and feeding habits, relevant autecological data, functional morphology (e.g., morphological differences in feeding apparatus), habitat (e.g., substrate), species associations, and living analog species when appropriate, and have been similarly inferred for paleocommunities elsewhere (Angielczyk et al. 2005; Butterfield 2001; 
Dunne et al. 2008; Dunne et al. 2014; Mitchell et al. 2012; Roopnarine et al. 2018; Roopnarine 2009; Roopnarine \& Angielczyk 2015). Differences between paleo-food webs relative to modern food webs also have a negligible effect on guild diversity, network structure, and functioning (Roopnarine \& Dineen 2018). See Roopnarine (2006, 2009, 2010) for a more thorough treatment of paleo-food web reconstruction in ecological network modeling.

CEG models specifically account for the uncertainty associated with paleocommunity data, and were used to assess stability (Roopnarine 2009; Roopnarine \& Dineen 2018; Roopnarine 2006) by perturbing randomly generated species-level networks and measuring the resultant proportion of secondary extinction. The model perturbs stochastically generated species-level networks constrained by the guild metanetwork structure, by systematically removing increasing proportions of primary producers. If the PBDB and SB data produce consistent ecosystem structure, the corresponding CEG models should have similar resistance to collapse. Resistance refers to an ecosystem's ability to remain unchanged when faced with ecological disturbances (Lockwood \& Pimm, 1994). The threshold of collapse occurs when the percentage of perturbation of primary producers results in secondary extinction at or near 100\%. 20 CEG models were generated for each of the four networks (PBDB and SB pre- and post-invasion). Generalist species from higher trophic levels should have many connections to other guilds, resulting in better resistance and recovery from perturbation (Lockwood \& Pimm 1994; Loreau \& Hector 2001; McCann 2000; Oliver et al. 2015; Roopnarine 2009). Therefore, if SB data includes fewer species from higher trophic levels than the PBDB, SB based models may have relatively lower stability and resistance. Alternatively, SB data may yield higher richness relative to the PBDB, if the number of species in the PBDB is reduced by outdated taxonomic identifications and "lumping" of taxa (Prothero 2015). If this is the case, SB based models may have greater stability and resistance relative to the PBDB-based models.

Generalities in network structure were calculated from the metanetwork using graph theory to examine properties of food web topology. Differences in trophic level metrics (i.e., number of trophic levels, average trophic level, trophic links) between data types before and after the invasion, would suggest that data type influences network structure. Network structure was examined by comparing the number of guilds, trophic links, average trophic level, and modularity of the SB and PBDB food webs before, and after the invasion. Modules represent subcommunities, or groups of trophic guilds with a greater density of mutual interactions (links) than interactions with other guilds, and modularity measures the strength of compartmentalization (Montoya et al. 2015; Strogatz et al. 2004). The number of modules and modularity were calculated using the walktrap community detection algorithm (Pons \& Latapy 2005).

Trophic level refers to a group of organisms within an ecosystem that represent the same level in a food chain. Average trophic level is a numerical average of trophic levels that best represents the amount of energy that flows through an ecosystem. The proportions of species and trophic guilds that are shared between the SB and PBDB were also compared across the invasion. As the PBDB includes a potentially greater species pool relative to museum collections, the PBDB may include greater numbers of rare taxa from higher trophic levels. We compared trophic levels between SB and PBDB datasets because we wanted to see if changes in trophic levels were recorded across the invasion event in both datatypes. Average trophic level is calculated using chain averaged trophic levels, which compute the mean position of each node in every unique food chain in a food web.

All analyses were conducted in $\mathrm{R}$ version 3.3.1 (R Development Core Team 2016) using custom script writer by Tyler. Network graphing and community detection were done using the 
"iGraph" package (Csardi \& Nepusz, 2006). Descriptive metrics were calculated in the 'NetIndices' package (Kones et al. 2009). Modularity, link totals, average trophic level, and node totals were calculated in R using “cheddar" (Hudson et al. 2012).

\section{Results}

The SB data had a greater abundance and richness than the PBDB data both preand post-invasion (Tables 1 and 2). The SB data included 3,591 pre-invasion specimens versus 387 specimens in the PBDB, and 4,858 in the SB data post-invasion relative to 167 in the PBDB. In the SB data pre-invasion there were 274 species relative to 157 in the PBDB, and 195 species in the SB post-invasion compared with 131 in the PBDB. All species from field collections were present in museum collections pre- and post-invasion, and there was a $45 \%$ overlap in species between the museum collections data and the field data pre-invasion, and $72 \%$ shared species postinvasion (Table 1). Similarly, high percentages of shared species occurred in the PBDB data, and $63 \%$ of the pre-invasion species present in the PBDB were also present in the combined SB data pre-invasion, and $85 \%$ were shared post-invasion.

CEG models constructed using SB data were highly congruent across the invasion (Figure 3 A-B). The magnitude of secondary extinction was notably uniform pre- and postinvasion, with little variation in the proportions of secondary extinction before and after the collapse threshold. In both SB models, secondary extinction remained low until a magnitude of perturbation of $\sim 0.6$, after which secondary extinction and complete collapse became frequent. However, in the pre-invasion SB CEG, $100 \%$ secondary extinction was never reached, and a buffer was present at approximately $90 \%$ which was not apparent in the pre-invasion PBDB model. Using the PBDB data, model responses to perturbation were highly variable before and after the invasion (Figure 3 C-D), and in both the pre- and post-invasion PBDB CEGs, secondary extinction varied between $\sim 20-70 \%$ before the threshold of collapse. Secondary extinction remained volatile until a magnitude of perturbation of $\sim 0.75$, after which secondary extinction and complete collapse became frequent. Two steps up in the proportion of secondary extinction were visible in the preinvasion model $\sim 0-0.3$ and $0.3-0.75$ perturbation magnitudes. However, these were absent in the post-invasion model.

Network structure was relatively consistent between data types (Figure 3). The number of guilds range from 20-23, however, relative changes across the invasion varied depending on data source (Table 2). In the SB network, the number of guilds increased after the invasion from 20 to 21, while in the PBDB network, the number of guilds decreased from 23 to 21. However, both networks contain identical guilds after the invasion. Similarly, the number of links (i.e., interactions) ranged from 54-63, but relative changes varied. The number of links increased postinvasion in the SB network, from 54 to 56, and decreased post-invasion in the PBDB network from 63 to 56. There were three modules in all four networks, and modularity increased post-invasion for both the SB and PBDB networks (Table 2). The proportion of omnivory was also relatively consistent in all four networks, and also increased post-invasion for both the SB and PBDB networks, as did the average trophic level.

When looking at the structure of the metanetworks, it is also important to determine which guilds are present in each network (Table 3). The pre-invasion SB dataset is missing the "Bacteria" guild, the "Grazer I" guild, the "Suspension Feeder VII" guild, the "Predator VI" guild, and the "Predator VII" guild. The "Bacteria" guild was not included because the only predator in our networks that eats bacteria is a group of predatory worms that make up the "Predator VI" guild. 
This does not mean that bacteria were not present in the ecosystem, but rather that the only guild interaction there was evidence for with bacteria (based on the literature) was not present. The "Grazer I" and "Predator VI" guilds are both guilds composed of worms and were not present in our pre-invasion SB network. The "Suspension Feeder VII" guild consisted of suspension feeding trilobites that were not present in the pre-invasion SB dataset. These missing organisms, however, were present in the pre-invasion PBDB dataset. In the pre-invasion PBDB dataset, the "Detritivore II" and "Predator VII" guilds are missing. The "Detritivore II" guild is composed of annelid worms that were not present in the pre-invasion PBDB dataset. It is important to note that the guild composition of the SB and PBDB datasets within modules were very similar (Table 3). Module 1 included eight guilds present in both the SB and PBDB networks, and Module 3 included six guilds present in both. Module 2 did not share any guilds, but any differences shown in module composition could be due to the groups missing between the SB and PBDB datatypes.

In both pre-invasion datasets, the "Predator VII" guild was not present. This guild included large predatory arthropods, such as eurypterids, which were not present in the pre-invasion species lists. Interestingly, both post-invasion datasets have identical module composition and guilds present and both datatypes are missing the following guilds post-invasion: "Detritivore II", "Grazer I", "Suspension Feeder II, and "Suspension Feeder VII". "Predator VII" is also added to both post-invasion datasets.

\section{Discussion}

The SB and PBDB datasets differed notably in abundance and species richness both preand post-invasion. Despite these differences in data composition, both recorded a reduction in species richness after the invasion. However, CEG models varied between data types in several important ways. In the pre-invasion SB CEG model, secondary extinction never surpassed 90\%, and a small subset of species persisted indefinitely, even at perturbation magnitudes of 1 . In contrast, the PBDB model frequently collapsed entirely (i.e., reached $100 \%$ secondary extinction) at perturbation magnitudes above $\sim 0.75$, and models constructed using the PBDB data failed to capture this stability. Although resistance was lower in both the pre- and post-invasion SB models relative to the PBDB models, the threshold of collapse was comparable across the invasion within data types. Thus, while absolute values of resistance were inconsistent between the SB and PBDB models, trends within data types were consistent. Most notable was the volatility observed in secondary extinction cascades in both PBDB CEG models relative to the SB models. Overall, the PBDB data yielded less resistant and less stable paleocommunities, as indicated by higher thresholds of collapse, highly variable ranges in the proportions of secondary extinction, and 100\% collapse after a perturbation magnitude of $\sim 0.75$. This suggests that the higher richness of the SB data relative to the PBDB, possibly an artifact of outdated taxonomic identifications and/or "lumping" of taxa as suggested by Prothero (2015), proved important in modeling community dynamics.

Generalities in network structure suggest that the metanetwork structure of the SB models was relatively similar to that of the PBDB models, but did not agree for all descriptive metrics. In the SB networks, both the number of guilds and links increased after the invasion, while this trend was reversed in networks created using the PBDB. However, these changes across the invasion were relatively minor and their significance is difficult to evaluate. Compartmentalization was consistent between networks of different data types, and across the invasion. Furthermore, pre-invasion guild membership was identical within modules between the SB and PBDB networks, 
as were the guild memberships of modules in the post-invasion networks. The strength of the division into subcommunities (i.e., modularity) also increased in both post-invasion networks. As compartmentalization may increase network stability and persistence (Gross et al. 2009; Newman 2006; Stouffer \& Bascompte 2011) preventing the propagation of perturbations between modules (Krause et al. 2003; Newman 2006), these metrics would provide important evidence for ecological interpretations of the outcome of invasion. Similarly, the average trophic level was relatively invariable (but increased marginally in both post-invasion networks), as was the proportion of omnivory (although omnivory did decrease from $60 \%$ to $57 \%$ after the invasion in the SB network). Greater omnivory may increase the number of connections to multiple trophic levels and the structural complexity of the network (Kratina et al. 2012; Polis \& Strong 1996; Bascompte et al. 2005). Greater proportions of omnivory may, therefore, moderate strong trophic interactions and indirect effects of a top or bottom level trophic level on the entire ecosystem. Thus, the proportion of omnivory may play an integral role in network resistance and stability in some cases. Given the consistency between metrics quantifying modules, modularity, trophic levels, and omnivory, either data type are likely to be appropriate for studies utilizing these analyses to assess paleocommunity structure and functioning.

These findings are consistent with studies comparing modern food webs to simulated fossil food webs (Roopnarine \& Dineen 2018), where differences in the number of species, guilds, and links do not alter network properties.

\section{Conclusions}

Given that both data types produced similar numbers of guilds and links despite differences in richness, these results suggest that the PBDB could serve as an accessible and reliable data resource suitable for food web reconstructions utilizing descriptive metrics to assess network structure and functioning. However, studies modeling stability and community dynamics should consider the potential differences in paleocommunity dynamics that may arise between data types. Questions relying on relative differences are likely appropriate for either data type, but in cases where absolute values are considered, museum collections may be preferable. 


\section{References}

Alroy, John. 2002. "How Many Named Species Are Valid?” Proceedings of the National Academy of Sciences 99 (6): 3706-11.

—. 2003. "Global Databases Will Yield Reliable Measures of Global Biodiversity." Paleobiology 29 (1): 26-29.

Angielczyk, K. D., P. D. Roopnarine, and S. C. Wang. 2005. "Modeling the Role of Primary Disruption in End-Permian Extinctions, Karoo Basin, South Africa." Natural History and Science Bulletin, no. 30.

Bascompte, Jordi, Carlos J. Melián, and Enric Sala. 2005. "Interaction Strength Combinations and the Overfishing of a Marine Food Web." Proceedings of the National Academy of Sciences 102 (15): 5443-47.

Brett, Carlton E, and Gordon C Baird. 1986. "Comparative Taphonomy : A Key to Paleoenvironmental Interpretation Based on Fossil Preservation.” Palaios 1 (3): 207-27.

Butterfield, N. 2001. “Cambrian Food Webs.” In Paleobiology II: A Synthesis, edited by P. R. Briggs, D. E. G. \& Crowther, 40-43. Blackwell Scientific.

Cadotte, Marc W., Kelly Carscadden, and Nicholas Mirotchnick. 2011. "Beyond Species: Functional Diversity and the Maintenance of Ecological Processes and Services." Journal of Applied Ecology 48 (5): 1079-87.

Csardi, G, and T Nepusz. 2006. "The Igraph Software Package for Complex Network Research, InterJournal, Complex Systems.”

Davis, Richard A., and David L. Meyer. 2009. A Sea without Fish: Life in the Ordovician Sea of the Cincinnati Region. Indiana University Press.

Dunne, Jennifer A., Conrad C. Labandeira, and Richard J. Williams. 2014. "Highly Resolved Early Eocene Food Webs Show Development of Modern Trophic Structure after the EndCretaceous Extinction.” Proceedings of the Royal Society B: Biological Sciences 281: 20133280.

Dunne, Jennifer A., Richard J. Williams, Neo D. Martinez, Rachel A. Wood, and Douglas H. Erwin. 2008. "Compilation and Network Analyses of Cambrian Food Webs." PLoS Biology 6 (4). Public Library of Science: 693-708.

Feldman, and Hackathorn. 1996. Fossils of Ohio. State of Ohio, Dept of Natural Resources.

Frey, R. W., and S. G. Pemberton. 1985. "Biogenic Structures in Outcrops and Cores. I. Approaches to Ichnology." Bulletin of Canadian Petroleum Geology 33 (1): 72-115. 
Froyd, C.A., and K.J. Willis. 2008. "Emerging Issues in Biodiversity and Conservation Management: The Need for a Palaeoecological Perspective." Quaternary Science Reviews 27 (17-18): 1723-32.

Gross, L, L Rudolf, SA Levin, and U Dieckmann. 2009. “Generalized Models Reveal Stabilizing Factors in Food Webs." Science 325 (5941): 747-50.

Holland, S. M. 1993. "Sequence Stratigraphy of a Carbonate-Clastic Ramp: The Cincinnatian Series (Upper Ordovician) in Its Type Area." Geological Society of America Bulletin.

Holland, S. M., and M. E. Patzkowsky. 2007. "Gradient Ecology of a Biotic Invasion: Biofacies of the Type Cincinnatian Series (Upper Ordovician), Cincinnati, Ohio Region, USA." Palaios 22: 392-407.

Hudson, Lawrence N., Rob Emerson, Gareth B. Jenkins, Katrin Layer, Mark E. Ledger, Doris E. Pichler, Murray S. A. Thompson, Eoin J. O'Gorman, Guy Woodward, and Daniel C. Reuman. 2012. "Cheddar: Analysis and Visualisation of Ecological Communities." Methods in Ecology and Evolution 4 (1): 99-104.

Jackson, Jeremy B C, Michael X Kirby, Wolfgang H Berger, Karen A Bjorndal, Louis W Botsford, Bruce J Bourque, Roger H Bradbury, et al. 2001. "Historical Overfishing and the Recent Collapse of Coastal Ecosystems.” Science 293 (5530): 629 LP-637.

Kones, J.K., K. Soetaert, D. van Oevelen, and J. Owino. 2009. "Are Network Indices Robust Indicators of Food Web Functioning? A Monte Carlo Approach." Ecological Modelling 220 (3): $370-82$.

Kratina, P., M. LeCraw, T. Ingram, and B. Anholt. 2012. "Stability and Persistence of Food Webs With Omnivory: Is There a General Pattern?" Ecosphere 3(6) (50).

Krause, Ann E., Kenneth A. Frank, Doran M. Mason, Robert E. Ulanowicz, and William W. Taylor. 2003. "Compartments Revealed in Food-Web Structure." Nature 426: 282-85.

Lockwood, Julie L., and Stuart L. Pimm. 1994. "Biological Diversity: Species: Would Any of Them Be Missed?” Current Biology 4 (5): 455-57.

Loreau, M, and A Hector. 2001. "Biodiversity and Ecosystem Functioning : Current Knowledge and Future Challenges" 294 (October): 804-9.

Malizia, Richard W., and Alycia L. Stigall. 2011. "Niche Stability in Late Ordovician Articulated Brachiopod Species Before, During, and after the Richmondian Invasion." Palaeogeography, Palaeoclimatology, Palaeoecology 311 (3-4): 154-70.

McCann, Kevin, Alan Hastings, and Gary R. Huxel. 1998. "Weak Trophic Interactions and the Balance of Nature." Nature 395 (6704): 794-98. 
McCann, Kevin Shear. 2000. “The Diversity-Stability Debate.” Nature 405: 228-33.

McKerrow, W.S., and C.R. Scotese. 1990. "Revised World Maps and Introduction.” Palaeozoic Palaeogepgraphy and Biogeography, Geolocial Society Memoir, no. 12: 1-21.

Mitchell, Jonathan S, Peter D Roopnarine, and Kenneth D Angielczyk. 2012. "Late Cretaceous Restructuring of Terrestrial Communities Facilitated the End-Cretaceous Mass Extinction in North America." Proceedings of the National Academy of Sciences of the United States of America 109 (46): 18857-61.

Montoya, D, M L Yallop, and J Memmott. 2015. "Functional Group Diversity Increases with Modularity in Complex Food Webs." Nat Commun 6.

Newman, M.E. J. 2006. "Modularity and Community Structure in Networks." Proceedings of the National Academy of Sciences 103 (23): 8577-82.

O’Gorman, E. J., J. M. Yearsley, T. P. Crowe, M. C. Emmerson, U. Jacob, and O. L. Petchey. 2011. "Loss of Functionally Unique Species May Gradually Undermine Ecosystems." Proceedings of the Royal Society B: Biological Sciences 278 (1713): 1886-93.

Oliver, Tom H., Matthew S. Heard, Nick J B Isaac, David B. Roy, Deborah Procter, Felix Eigenbrod, Rob Freckleton, et al. 2015. "Biodiversity and Resilience of Ecosystem Functions." Trends in Ecology \& Evolution 30 (11): 673-84.

Paine, R. T. 1992. "Food-Web Analysis through Field Measurement of per Capita Interaction Strength." Nature 355 (6355): 73-75.

Patzkowsky, M.E., and S.M Holland. 1996. "Extinction, Invasion, and Sequence Stratigraphy; Patterns of Faunal Change in the Middle and Upper Ordovician of the Eastern United States." In Paleozoic Sequence Stratigraphy: Views from the North American Craton, edited by G.A. Witzke, B., Day, J., and Ludvigson, 306thed., 131-42.

Patzkowsky, Mark E, and Steven M Holland. 2007. "Diversity Partitioning of a Late Ordovician Marine Biotic Invasion: Controls on Diversity in Regional Ecosystems." Paleobiology 33 (2): 295-309.

Polis, G. A., and D. R. Strong. 1996. "Food Web Complexity and Community Dynamics." American Naturalist 147 (5): 813-46.

Ponder, W F, G A Carter, P Flemons, and R R Chapman. 2001. "Evaluation of Museum Collection Data for Use in Biodiversity Assessment." Conservation Biology 15 (3): 648-57.

Pons, Pascal, and Matthieu Latapy. 2005. "Computing Communities in Large Networks Using Random Walks." Computer and Information Sciences (ISCIS) 10: 284-93.

Pope, M, and JF Read. 1997. "High-Resolution Surface and Subsurface Sequence Stratigraphy of Late Middle to Late Ordovician (Late Mohawkian-Cincinnatian) Foreland Basin Rocks, 
Kentucky and Virginia." AAPG Bulletin: American Association of Petroleum Geologists 81 (11): 1866-93.

Prothero, D R. 2015. "Garbage In, Garbage out: The Effects of Immature Taxonomy on Database Compilations of North American Fossil Mammals.” In Fossil Record 4: Bulletin 67, 257-64.

R Development Core Team. 2016. "R: A Language and Environment for Statistical Computing." R Foundation for Statistical Computing.

Roopnarine, P. D. 2009. "Ecological Modeling of Paleocommunity Food Webs." The Paleontological Society Papers 15: 195-220.

Roopnarine, P. D., and K. D. Angielczyk. 2015. "Community Stability and Selective Extinction During the Permian-Triassic Mass Extinction.” Science 350 (6256): 90-93.

Roopnarine, P. D., and A. L. Dineen. 2018. "Coral Reefs in Crisis: The Reliability of Deep-Time Food Web Reconstructions as Analogs for the Present." In Marine Conservation Paleobiology, edited by C. L. Tyler and C. L. Schneider, 105-41. Springer Cham.

Roopnarine, Peter D. 2006. "Extinction Cascades and Catastrophe in Ancient Food Webs." Paleobiology 32 (1): 1-19.

. 2010. "Networks, Extinction, and Paleocommunity Food Webs." In QuantitatIve Methods In Paleobiology, edited by John Alroy And Gene Hunt, 143-61. The Paleontological Society.

Roopnarine, Peter, Allen Weik, Kenneth Angielczyk, and Ashley Dineen. 2018. "Stability, Incumbency and Ecological Reorganization after the Permian-Triassic Mass Extinction." bioRxiv.

Stigall, Alycia L. 2010. "Using GIS to Assess the Biogeographic Impact of Species Invasions on Native Brachiopods during the Richmondian Invasion in the Type-Cincinnatian (Late Ordovician, Cincinnati Region)." Palaeontologica Electronica 13 (1): 1-19.

Stouffer, D. B., and J. Bascompte. 2011. "Compartmentalization Increases Food-Web Persistence.” Proceedings of the National Academy of Sciences 108 (9): 3648-52.

Strogatz, S.H. H, Tamara N Romanuk, Yun Zhou, Ulrich Brose, E.L. Eric L Berlow, R.J. RJ Richard J Williams, N.D. Neo D ND Martinez, et al. 2004. "Integrating Paleobiology, Archeology, and History to Inform Biological Conservation." Nature 27 (1): 45-54.

Williams, Alwyn, S J Carlson, and C H C Brunton. 2000. "Brachiopod Classification.” In Treatise on Invertebrate Paleontology Part H Brachiopoda Revised, 2: Linguli:1-21.

Williams, R.J., and N.D. Martinez. 2000. "Simple Rules Yield Complex Food Webs.” Nature 
404: 180-83.

Willis, K J, and H J B Birks. 2006. "What Is Natural? The Need for a Long-Term Perspective in Biodiversity Conservation." Science 314 (5803): 1261-65. 


\section{Tables and Figures}

Table 1. Species counts for pre- and post-Richmondian invasion by data type. $\mathrm{N}$ represents abundances, richness refers to the number of species, and the percentage of shared species refers to the percentage of species shared between the SB and PBDB datasets. The percentages of shared species for both museum and field collections are compared to the PBDB dataset, while the percentage of shared species for the PBDB is the percentage of species shared between the PBDB and museum datasets.

\begin{tabular}{|l|l|l|r|r|r|r|r|}
\hline \multicolumn{2}{l|}{} & \multicolumn{3}{l|}{ Pre-Invasion } & \multicolumn{3}{l|}{ Post-Invasion } \\
\hline Sources & Data Type & N & Richness & \% Shared Species & N & Richness & \% Shared Species \\
\hline Field & SB & 2851 & 27 & 100 & 3016 & 32 & 100 \\
\hline Museum & SB & 370 & 286 & 45 & 1842 & 261 & 72 \\
\hline PBDB & DB & 387 & 158 & 63 & 384 & 167 & 85 \\
\hline
\end{tabular}

Table 2. Metrics comparison of SB and PBDB food webs across the invasion event. Note that the number of modules stays constant throughout, modularity increases in both datatypes, and the number of species decreases in both datatypes.

\begin{tabular}{|r|r|r|r|r|}
\cline { 2 - 5 } \multicolumn{1}{c|}{} & \multicolumn{2}{c|}{ SB Food Web } & \multicolumn{2}{c|}{} \\
\hline Dataset & Pre & Post & Pre & Post \\
\hline Number of Species & 274 & 195 & 157 & 131 \\
\hline Number of Guilds & 20 & 21 & 23 & 21 \\
\hline Number of Links & 54 & 56 & 63 & 56 \\
\hline Number of Modules & 3 & 3 & 3 & 3 \\
\hline Modularity & 0.287 & 0.320 & 0.251 & 0.320 \\
\hline \% Omnivory & 0.60 & 0.57 & 0.57 & 0.57 \\
\hline Average Trophic Level & 2.41 & 2.44 & 2.35 & 2.44 \\
\hline
\end{tabular}


Table 3. Guilds present in food webs for SB and PBDB datasets. Numbers dictate the module in which the guild is present. Colors correlate to the network guild visualizations. Guilds that are not present are highlighted in red and marked as not present (NP) in the network.

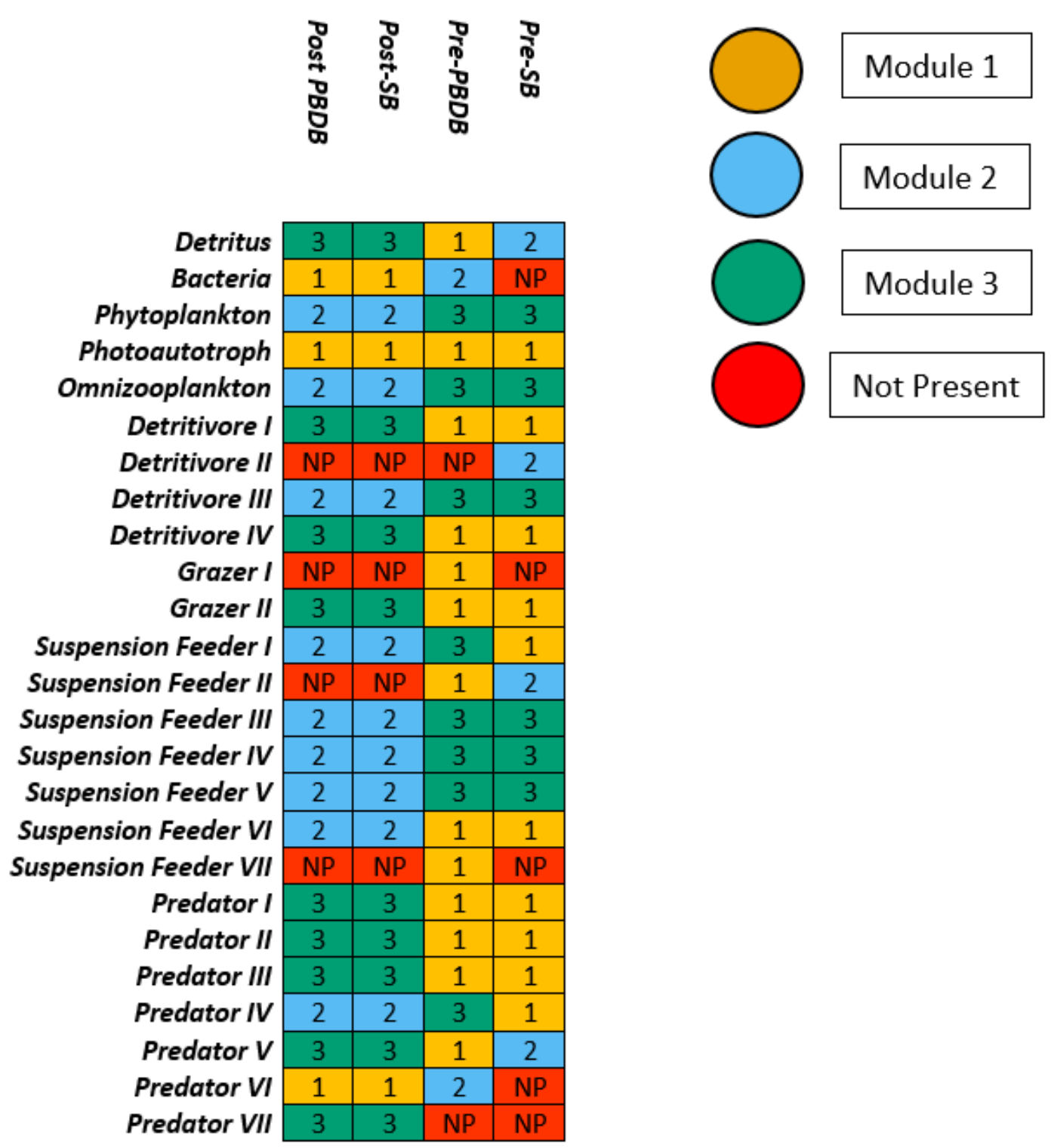


Figure 1. Depositional sequences and lithology in relation to proposed changes community stability. The stars indicate the formations used. The colors of the formations indicate the paleoenvironment and range from close to shore (lighter coloration) to offshore (darker coloration). The formations used in this study represent shallow subtidal (highlighted by grey color) and deep subtidal (highlighted by dark grey color). The C2 sequence, which contains the pre-invasion data, is highlighted in yellow, the Richmondian invasion is highlighted in red, and the C5 sequence, which contains the post-invasion data, is highlighted in blue.

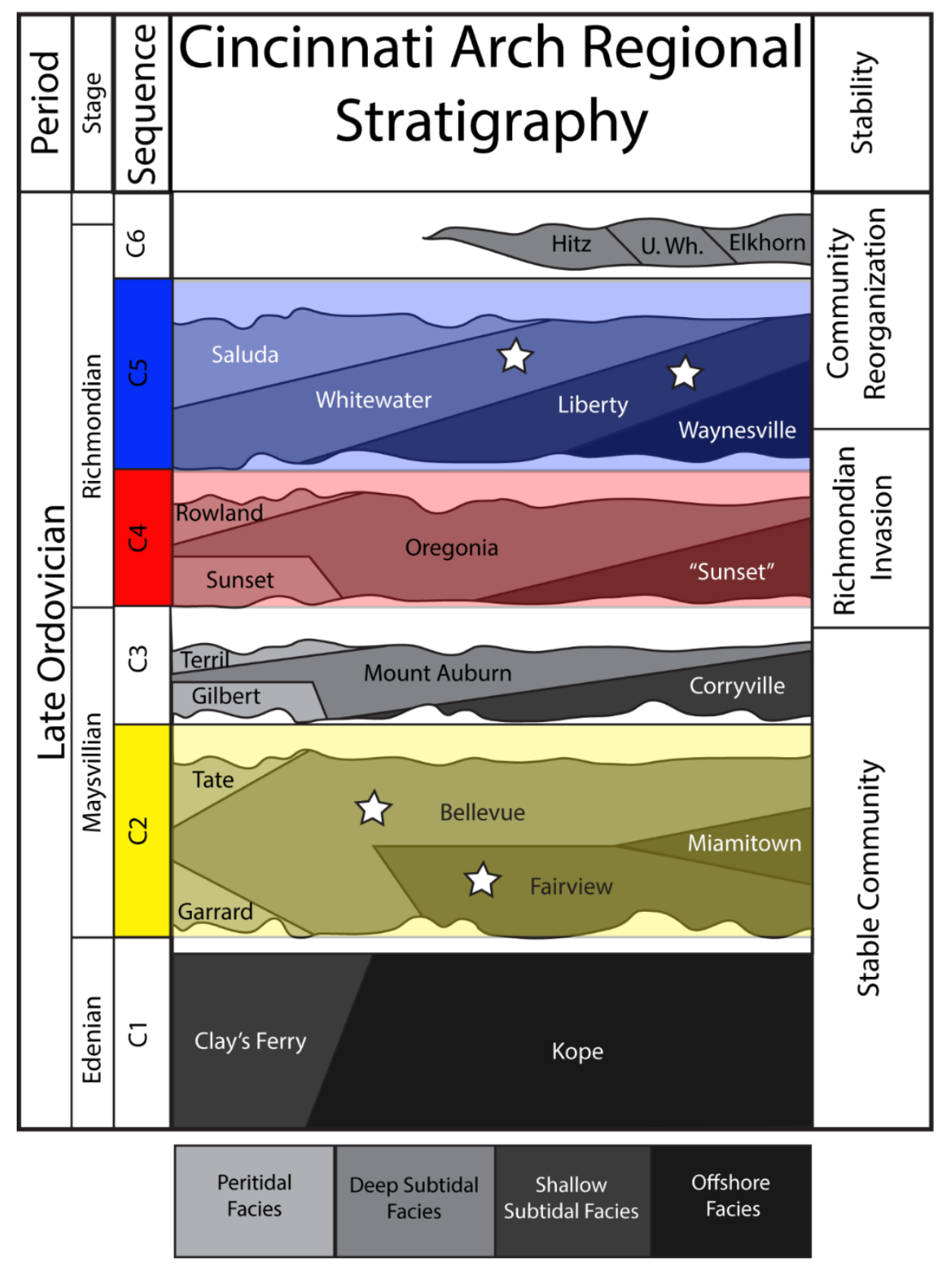


Figure 2. Locality map for field sampling. Colors differentiate between pre- (blue squares) and post- invasion (red circles) sites. The dark grey area represents the extent of Ordovician rock exposure in the region.

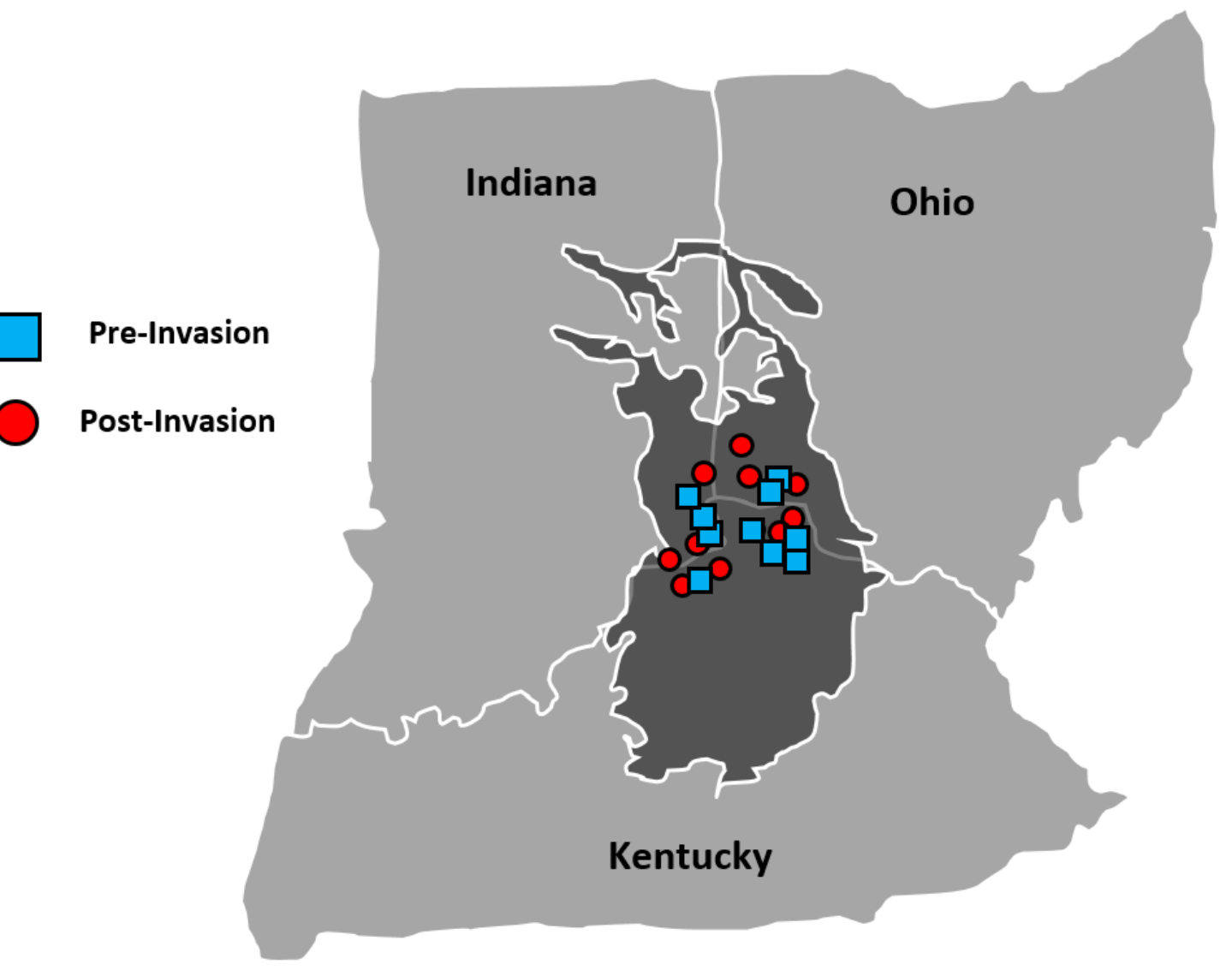


Figure 3. Cascading extinction on graphs (CEG) models for the pre-invasion SB (A), postinvasion SB (B), pre-invasion PBDB (C) and post-invasion PBDB (D) data. Dashed line denotes threshold of collapse. Note similarity in where collapse occurs in A-D, almost identical structure in SB data (A-B) and differences in ranges of secondary extinction in PBDB data (C-D).
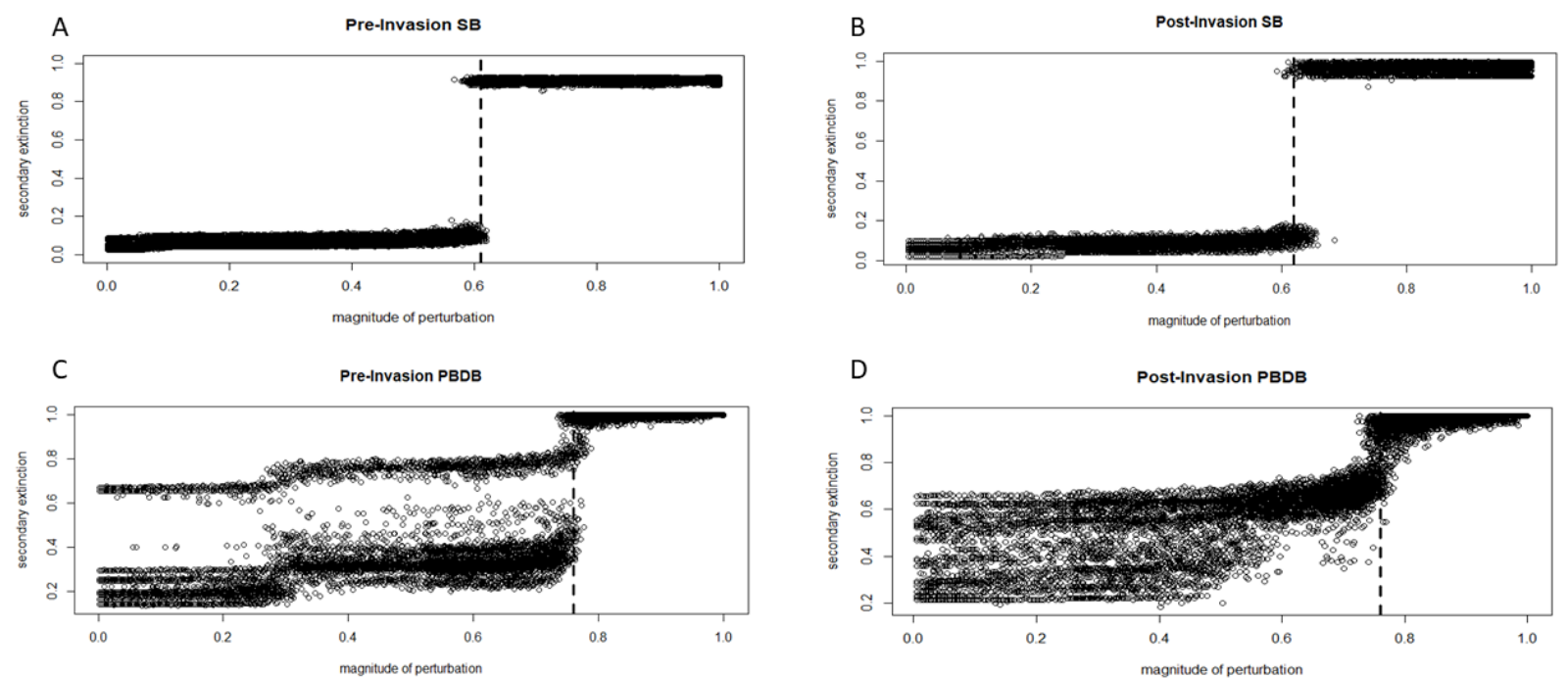
Figure 4. Network guild visualizations of the pre-invasion SB (A), pre-invasion PBDB (B), post-invasion SB (C), and post-invasion PBDB (D) datasets. The colors of the circles differentiating between the three modules (subcommunities), and modules are circled with different colors. Red arrows show interactions across modules. Names are of trophic guilds.
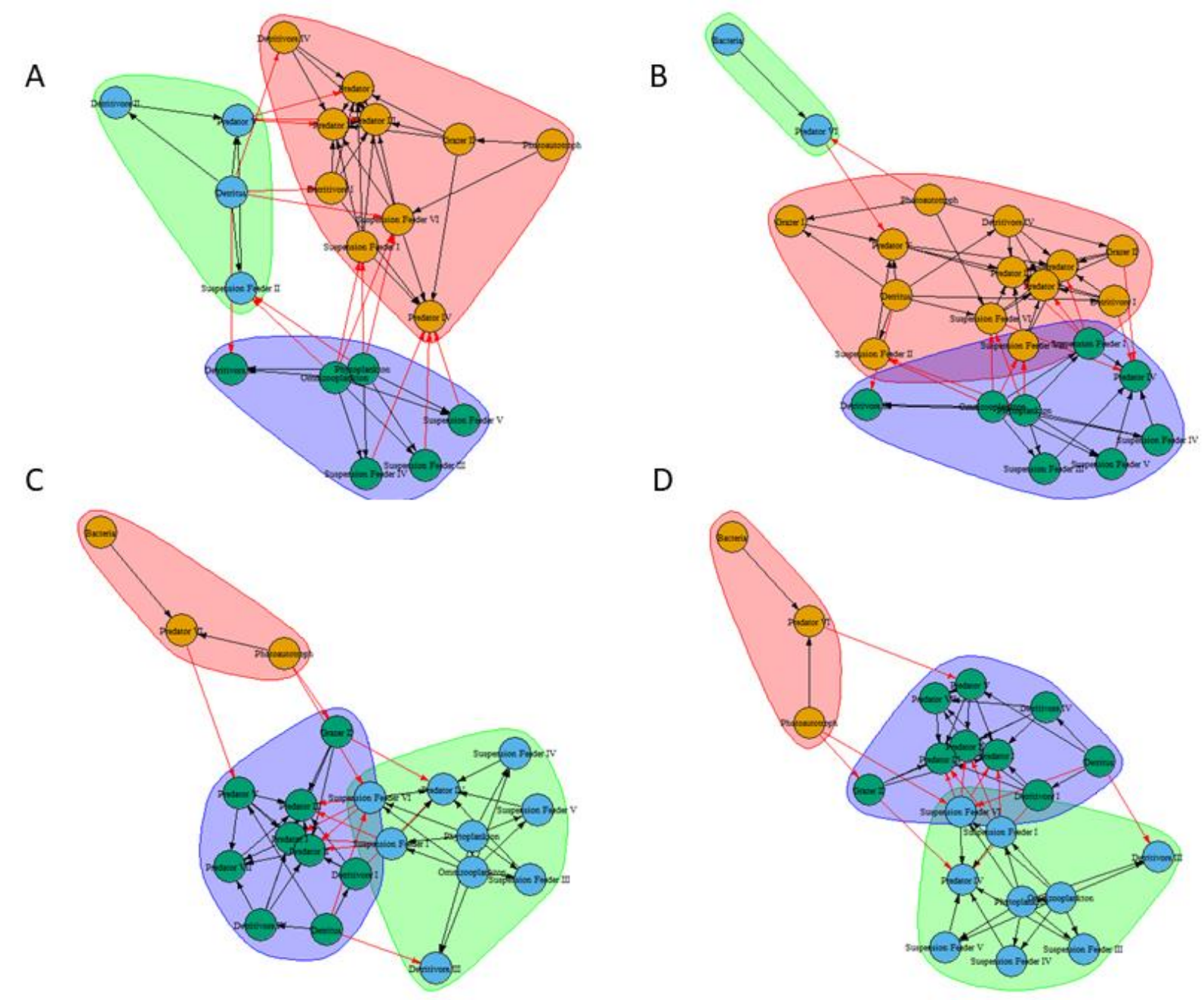